\title{
Interdisciplinary Convergence Research Design on Island Biocultural Diversity - Case Study in Wando-gun (County) Island Region, South Korea
}

\author{
Hong, Sun-Kee (corresponding author) \\ Institution for Marine and Island Cultures, Mokpo National \\ University, Songrim-gil 41-11, Mokpo, Republic of Korea \\ landskhong@gmail.com
}

Lee, Gyeong-A

Institution for Marine and Island Cultures, Mokpo National University, Songrim-gil 41-11, Mokpo, Republic of Korea

\section{Cho, Mi-Ra}

Institution for Korea Language and Literature, Mokpo National University Yeongsan-ro 1666, Cheonggye myeon Muan-gun Jeollanam-do, Republic of Korea

Kim, Jae-Eun

Institution for Marine and Island Cultures, Mokpo National University, Songrim-gil 41-11, Mokpo, Republic of Korea

\author{
Won, Yong-Tae \\ Institution for Marine and Island Cultures, Mokpo National \\ University, Songrim-gil 41-11, Mokpo, Republic of Korea
}

\section{Han, Eun-Seon}

Institution for Marine and Island Cultures, Mokpo National University, Songrim-gil 41-11, Mokpo, Republic of Korea

\section{Park, Hye-Yeong}

Institution for Marine and Island Cultures, Mokpo National University, Songrim-gil 41-11, Mokpo, Republic of Korea

\section{Samantha Chisholm Hatfield}

Institution for Marine and Island Cultures, Mokpo National University, Songrim-gil 41-11, Mokpo, Republic of Korea Oregon State University Oregon Climate Change Research Institute, Strand Ag 327 Corvallis, Oregon 97331 USA

Publication Information:

Received 12 April 2018, Accepted 16 May 2018, Available online 30 June 2018

doi: 10.21463/jmic.2018.07.1.02

\section{Abstract}

The purpose of this research is (1) to study the epistemological meanings of biological diversity and cultural diversity and the connectivity of biocultural diversity and (2) to concretize a plan for making the biocultural diversity, containing the ecological environment and the life culture of the island areas, into knowledge resources. By carrying out onsite 
investigations, in-depth interviews, and the empirical case example research with the Wando County area of Jeonnam Province as the subject, (3) the possibility of the agenda is presented through the interdisciplinary convergence researches, including but not limited to: biology, anthropology, linguistics, Korean literature, folklore, cultural contents study. As a plan for putting into practice the convergence research, the theoretical foundations, the methodologies of the biological diversity and the cultural diversity of the islands can be systematically established through the research on the biocultural diversity of the islands and the excavation of the agenda. The theoretical foundations, the methodologies of biological diversity, and the cultural diversity of the islands can be systematically established. Through this establishment, the conceptual and the epistemological expansion of the biocultural diversity of the islands through the convergence of biological diversity and cultural diversity will be induced. This convergence research will contribute to the securing of the biological sovereignty and cultural sovereignty of the island people through the biological resources of the islands. Through the research on biocultural diversity of the islands, it will contribute in promotion of awareness on resource security regarding the approach to, and the sharing of, genetic resources in accordance with the biological diversity agreement. In addition, the preservation of biological, and genetic resources of the islands based on Traditional Ecological Knowledge (TEK) of the island people and direction for sustainable development will be pursued. Groundwork will also be laid for future endeavors, through establishment of Traditional Knowledges (TK), traditional local foods, recipes, and medical folk traditions, all based on the biological diversity. A plan for the resources will be prepared by excavating cultural traditions contained in the information from the biological diversity data along with linguistic diversity information, and through the establishment of an archive through the convergence research.

\section{Keywords}

biodiversity, Cheongsando, cultural diversity, biocultural diversity, interdisciplinary convergence research, island, island biogeography, linguistic diversity, Traditional Ecological Knowledge (TEK), Traditional Knowledge (TK), Wando

\section{Introduction}

After the 1990s, discussions regarding the linkage between biological diversity and cultural diversity proceeded vigorously. The concepts of 'bioculture' and 'biocultural diversity', which are the points of contact where the borders of the two fields met, emerged. The conceptual definitions and a few main topics are stated below. Looking specifically at the discussions by Maffi (Maffi, 1998; Rapport, 2006; Pretty et al., 2009; Maffi and Woodley, 2010):

- Biocultural diversity comprehensively includes the diversity of life and all the things that are manifested biologically, culturally, and linguistically in relation to it. Regarding biocultural diversity, everything is mutually connected (or mutually evolves) within the complex socio-ecological adaptation system.

- Diversity of life is organized with not only the diversity of the plant and animal species, habitats, ecosystems, but also, diversity of the cultures and languages of humans. This diversity does not exist as divisions or parallel ranges, instead it exists where the sole complex systems are manifested differently from each other. The connection between diversities develops by going through global effects of the mutual adaptation method, the same format as coevolution appears between humans and the environment within a region or natural world. 
'Bioculture' gets formed, developed, and changed through the spaces called "landscapes" (Maffi and Woodley, 2010; Hong et al., 2014). The diversities of the landscapes that create the biodiversity and cultural diversity deal with the survival of human beings who are very closely related with the traditional life and associated natural resources.

Traditional Knowledges (TK) and Traditional Ecological Knowledges (TEK) are widely discussed topics in academia and the definitions can vary according to culture, region, or geographic location. Defined here, Traditional Knowledge(s) (TK): overall information that encompasses a wide variety of general overarching traditional practices that are foundational bases for a given Indigenous traditional culture. May include, but is not limited to: storytelling, seasonality, phenology, and identification of cultural items, patterns, or traditions, genealogy (Chisholm Hatfield, 2018).

Traditional Ecological Knowledge (TEK) is the application of the specific area of Indigenous Traditional Knowledge and Indigenous Science Knowledge that specifically relates to the environment in a given traditional homeland of Indigenous groups and/or Usual and Accustomed (U\&A) areas. This may include but not limited to: botany knowledge, medicinal application (collection and/or administration), hunting, fishing, gathering, processing of material(s), caretaking such as burning, coppicing, thinning, astronomy, phenology, time, ecological markers, species markers, weather and climate knowledge (Chisholm Hatfield, 2018).

The important protection areas in the world, particularly areas such as sacred sites and holy places are indeed the places where the wisdom is most apparent regarding the use of natural resources through behaviors and traditions. This TK exhibited by the cultures that are representative within the long history of human beings. The residents have a longstanding history of protecting such sacred places, and they have been recognizing these places as the identities of the towns. This protection tradition is still evident currently, not only regarding the previously existent biodiversity but also the cultural diversity which includes such TK as recognitions, values, and the wisdom regarding nature are included (Berkes et al., 2000; UNESCO Universal Declaration on Cultural Diversity, 2001).

\section{Traditional Knowledge}

Biodiversity illustrates the ecological health and special, qualitative characteristics within natural ecosystems. Cultural diversity possesses the receptive capacity which is important in promoting the recovery ability of the social systems (Maffi, 1998). In order to guarantee retention containment regarding the knowledge and creation while maintaining the future of cultural diversity, the receptive capacity of human systems that adapt to changes must be promoted. Cultures that are different from each other have historically interacted through nature and through diverse methods (Hong et al., $2010,2014)$. They have been developing relationships, even though different from each other, in order to be able to adapt and fit their environments.

Main viewpoints of biodiversity are mainly distinguished into the species, the habits, and the ecosystems, influences of human beings on biota have been occurring on the landscape and area scales. Human beings have been continuously developing while simultaneously relying on nature. This reciprocal relationship humans have with natural resources is one of the basic TEK tenets, has been longstanding and is well documented (Nadasdy, 1999; Menzies, 2006). Because humans and nature are in a fated reliance, reciprocal relationship where humans cannot exist without the utilization of natural resources (Flenley and Bahn, 2003), the term 'biocultural diversity' was created and offers a clear meaning of the 
coexistence between nature and human beings (Maffi, 2001). The work is focused on re-recognizing the differences between the cultural diversity and the biological diversity, as well as the work regarding diffusion of the concept regarding biocultural diversity. Through this convergence research, the epistemological foundation regarding the biocultural diversity on the islands will be able to be widened.

In this article, the research on biocultural diversity in the island areas, is outlined regarding the biocultural diversity, which contains the ecological environment and the life culture of the island region, is discussed. It is also intended to present the possibility of the agenda through the interdisciplinary, convergence research. This is done through carrying out onsite investigations, in-depth interviews, and the empirical case examples from the islands in Jeonnam Province. This research includes but is not limited to: biology, ecology, literature, folklore, anthropology, the contents study, along with other interdisciplinary categories. The research results that are obtained through the phase work will be developed by being re-produced as an archive related to the diversity of the island creatures. The goal is to complete the academic convergence by going across academic boundaries and via natural communication while carrying out the joint research.

The research carried out on biocultural diversity is a field which is desperately needed (Pretty et al., 2009). Through interdisciplinary convergence research, results are obtained by going beyond the common limitations of long-established academic fields which are not providing enough data due to the limitation surrounding interdisciplinary studies. When looking at the subject in relation to environmental adaptation of the human beings to nature, the ecological imagination and the humanities imagination are like two sides of the same coin. While the academic interest of the islands has been increasing, the in-depth research conducted on the islanders' identity has been insufficient. The convergence research that puts the consilience research into practice through precedent research and research regarding facts and interpretations in diverse domains is needed. This research illustrates awareness regarding how to successfully form an academic network that involves multiple disciplines. This research is inclusive and multidisciplinary by involving the humanities, narrows the gaps between results, includes TK, as well as the approaches of social science research and natural science research, and includes the understanding and research pertaining to the islands (Hong, 2011a). At the present time, the need for the interdisciplinary and convergence research regarding biocultural diversities on the islands can be organized as the following.

\section{Goal of the research}

\section{The securing of the biological sovereignty and the cultural sovereignty of the island people}

Just as the biodiversity is an essential element in nature, cultural diversity acts as a root of exchanges, innovations, and creativity with regard to mankind. UNESCO defines 'culture' as "a whole of the special, psychological, material, intellectual, and emotional characteristics that show the personality of a society or a group and, also a comprehensivelyinclusive concept that includes the lifestyles and the basic rights, values, traditions, faiths, etc. of the human beings as a method of living together, not only the forms of the art and the characters" (UNESCO Universal Declaration on Cultural Diversity, 2001). Cultural diversity materializes the identities and the originalities of the groups and the societies that organize the whole of mankind. Additionally, the creations of a respective culture depend upon the unique cultural traditions and, at the same time, becomes abundant through contact with other cultures. Because of such these reasons, 
UNESCO has been emphasizing the enhancement of the originality that possesses the diversity and has been encouraging conversations between cultures by preserving and strengthening all forms of heritages. These heritages are the products of the experiences, and the records of, human beings and the traditional knowledge which is thereby transferred by delivering these to future generations (UNESCO, 2010).

The islands are the spaces in which progressive changes take place through contact exchanges which have become activated by crossing the seas. They are also the places that are isolated because cultural exchanges have been blocked or which possess locational conditions that are advantageous for the preservation of specific cultural identity. Due to the special, ecological feature of being surrounded by the sea on the four sides, the islands possess the contradictory characteristic of being simultaneously isolated and accessible. When seen from the cultural diversity aspect, the islands possess a uniqueness through the differences between an island onto itself, and an island located between the sea and the inland. The island residents have their own unique, cultural styles as well.

The 'Dadohae' Archipelago is a region that has maintained the ecological culture of the islands along with living species, the culture of the inlands becoming dispersed to the sea, and/or the biological diversity originating from the sea becoming integrated onto the inland (Hong, 2013). The human beings have been utilizing the surrounding landscapes and living species as vital life resources for long periods of time and, when necessary, have been developing new species through cultivations. The existence of the island ecosystems is very closely related with the daily lives of the residents that are constantly using the local biodiversity. The biodiversity of the islands has become the background foundation that promotes cultural diversity with regard to overall life culture including the food, clothing, and shelter of the island people. Here, the wisdom of life of the island people who have been living through sharing not only the transmission of the TK and the TEK surrounding the islands but also, biological resources as shared resources, is maintained. It is in this aspect that the cultural diversity of the islands is related to the cultural creation ability and heightened adaptation measures in order to maintain cultural ways (Chisholm Hatfield and Hong, 2017). Traditionally, the island people have established a method for developing technologies for a living as well as the tools that fit the ecological environment and for using these technologies rationally (Je et al., 2013). The changes of the town societies and other surrounding areas adjust to the changes of the ecological environment, such as the practice of using the community fisheries on the part of the fishermen, obtaining permission for fishery rights of the town, sea-inland reclamations, etc. are all items which are closely integrated with the identity of the local community.

There is a need to consider the methods of island living by using the wild plants and the trees that can be collected from mountains and fields on the island. These include but are not limited to: seaweeds, fish, salts that are be obtained and harvested from mud flats and the sea (Hong, 2014). Island people utilize natural resources creatively and are considered cultural assets of the local community (Berkes, 2004; Gadgil et al., 1993). There is a dire need to further study this aspect of cultural resource use, particularly since the research is intended to analyze data by delving into cultural circumstances of eating and living, formalities, health and medical life. These are all categories which islanders earn a living, through expanding fisheries management, based on the ecosystem, is managed by the residents of the island. Topics such as cultural rites, and resources used for medicinal information, are able to be collected and documented, the biodiversity of the island, and unique culture on each island, can be analyzed intricately. Based on the research regarding these aspects, the research will be able to contribute to the securing of biological and cultural sovereignty of the island people. 


\section{Cultural traditions between biological diversity and language diversity}

In Article 8(j) related to the TK, Innovations, and Practices of the Convention on Biological Diversity (CBD) of the International Union for Conservation of Nature (IUCN), the importance of not only the sustainable use and preservation of the biological diversity but, also, the TK resulting from the use of the biological resources is clearly indicated (International Conference on Biological and Cultural Diversity, 2010). In the final proposition adopted at the IUCN General Assembly held in Jeju Island in 2012, the members of the IUCN, the local governments, and the citizens groups urged the recognition of the importance of TE $\mathrm{K}$ for wise use of biological resources on the islands and coastal areas. Also urged were cautious actions for preservations, excavations, and the disseminations of TEK and biocultural diversity (Hong, 2013). In the Resolution XI/15 of the 11th Conference of the Parties of the Convention on Biological Diversity (CBDCOP11) regarding The Programme of Work on Island Biodiversity, it is clearly stated that "The traditional and cultural knowledge, technologies, and management methods that helped the island residents predict their environment and resources have been managed by going through several centuries." Additionally, in the Nagoya Protocol on Access to Genetic Resources and the Fair and Equitable Sharing of Benefits Arising from their Utilization, it is clearly indicated that "it is intended to recognize that an important measurement plan that helps the TK related to the use of the genetic resources on the islands has been presented."

Language diversity has an organic interrelationship with biodiversity. Biodiversity is inherited genetically by the species, and the cultural diversity is remembered generationally, and transmitted through language. Diversities of species and ecosystems are vitally important for mankind on earth for survival. Biodiversity is reflected expertly through TK. In precedent research, the overall, social phenomenon that occurs because a language mediates with the ecology is also called language-ecological (Birkhard 2015, Pennycook 2004, Creese and Blackledge, 2011), regarding ecological knowledge. In our research, attention is paid to the language and TEK, which remembers, records, and transmits accurate TEK in the form of a language as well as the ecological recognition data system of the island people. The diversity of a language also becomes a standard for identifying cultural diversity. The native islanders have generationally been accumulating TK along with the technologies related to the genetic resources, expressing this TK through language. For example, the native language that points to the high tides and the winds of the island shores in Jeonnam Province (including Yellow Sea of Korea) belong to the language system of the island people. The special, ecological features of the seaside, where the intertidal zones are located, along with the method of understanding the time and space of the island people have been embedded. The cycle of the high tides, knowledge on the fishing methods, topographies, fishing seasons, and the grammar, all possess cultural traditions which are uniquely exhibited in the language. The plans for the collection of materials for making such TK into resources, as well as the plans for an establishment of a database, are required.

\section{Resource security of genetic resource and sharing of the profits}

Biodiversity refers to the variation between the living bodies in all categories, including the land, marine and water ecosystems, the complex ecosystems in which these ecosystems materialize the parts, etc. Biodiversity can be divided into the following three levels: diversity within a species, the diversity between the species, and the diversity of the ecosystem (CBD, 1992; Richard, 2010). With the crisis of the island ecosystems and the decrease of organism diversity due to climate change, contamination, poorly planned development, the importance of the island organism diversity has 
been becoming increasingly eroded (Craig, 1994). Because of these impacts, the Convention on Biological Diversity was adopted at the United Nations Conference on Environment and Development (UNCED) which was held in Rio, Brazil, in 1992.

The Convention on Biological Diversity has three objectives. They are as follows: 1 . The conservation of biological diversity; 2 . The sustainable use of the bio-resources; 3 . The fair and equitable sharing of the benefits arising out of the utilization of the biological resources. Particularly, according to the third objective of the Convention on Biological Diversity, the countries rich in biological resources have been proceeding with negotiations by focusing on the restrictions on the use of the resources and the sharing of the profits. Additionally, countries that use the resources have been proceeding with the negotiations for smoothly using said biological resources. Consequently, the Nagoya Protocol, which dealt with the approach and the sharing of the profits regarding the genetic resources in the Convention on Biological Diversity (CBD), was adopted and came into effect on October 12, $2014^{1}$.

IUCN Resolution 5.115, which passed as a World Conservation Congress (WCC) initiative of the IUCN General Assembly in 2012, is aimed at strengthening biocultural diversity and TEK in Asia-Pacific island regions. The IUCN made this initiative effective so that international networks could be working through the diverse programs between 2013 and 2016. At the fifth World Conservation Congress (WCC) held in Jeju in September 2012, discussions regarding the preservation of biodiversity and sustainable utilizations of cultural resources of the island-coastal areas were pursued. In 2006, resolution was adopted by the 8th Conference of the Parties of the Convention on Biological Diversity, in Curitiba, Brazil, the biodiversity of the islands, costs, as well as the seas, were adopted as the main agenda. In February 2004, at the seventh Conference of the Parties of the Convention on Biological Diversity (CBD) in Kuala Lumpur, Malaysia), the issue of biological diversity of island areas was established as a new agendum. These island areas are the ecosystems that are most vulnerable to climate change effects and development processes.

As a countermeasure for these issues, there is an urgent need in Korea to deliberate on a plan for preservation of marine creature diversity through continued investigations of marine species in Korea, and securing genetic resources through classification and sampling work of indigenous marine species. Above all else, a policy for securing and expanding the sovereignty regarding the bio-resources of the islands, the establishment of a list for excavations, along with investigations for promoting the systematic securing, management, and utilization of bio-genetic resources of the islands, as well as the systematic foundation are urgently needed. Accordingly, our research team intends to carry out investigations with the case examples regarding the present situation of the bio-resources, management of the bioresources, actual condition of sharing of the profits, along with other pertinent issues within the Wando region in Jeonnam Province. Through organizing the investigation items for preservation of the populations of the species of the islands and evaluating the situation of the preservation, the elements that threaten the uniqueness of the islands in relation to the genetic resources will be identified. A strategy regarding the preservation, use, and management of the bio-genetic resources that fits the special, regional characteristics can then be formulated through research, enabling the possibility to cope with the international order in accordance with the Nagoya Protocol, preserving biodiversities in the regions of the southwest seashores, and contribute to the security of resources. 


\title{
The methodology of the research on the biocultural diversities of the islands
}

\author{
A questionnaire survey in relation to the utilization of the biodiversity
}

A questionnaire survey of the participating researchers, the NGO's, administrative organizations, and the island residents, related to the utilization of the biodiversity was administered. Humans cannot exist without the utilization of natural resources, and the reciprocal relationship is intrinsic. It is our view that the term 'biocultural diversity' was created in the meaning of the coexistence of the nature and the human beings. As such, it is an undeniable fact that human beings and nature have been mutually reliant on one another, have been in longstanding contact, and also, have been supplementing the ecological system. There is a need for the government, the researchers, the citizens, and the experts to understand that the connection point has been deteriorating due to global environmental changes. These changes have been rapidly increasing. Under-evaluated development projects, reduction of diversity of creatures, as well as other contributing factors are all indicators of this rapid environmental change. As a result, this research is intended to heighten the objective directionality of research by attempting to distribute a pointed questionnaire survey related to utilization of the biodiversity. This is directed not only with the participating researchers, but additionally NGO's, administrative organizations, and island residents.

\section{The participating observations and the interview investigations}

Cultural anthropology addresses topics of human culture particularly with respect to social structure, language, law, politics, religion, magic, art, and technology. Cultural anthropology integrates many kinds of diverse and different viewpoints by generally researching mutually relating aspects of behaviors, methods of thinking, culture and lifestyles of the human beings. This discipline strives to understand the essences of the aforementioned issues by integrating the viewpoints on human beings' cultures that are different from each other by having a viewpoint of the theory of the total (Donaldson and Myers, 2014). An approach including the relationship between species, the environment, and the culture but also is inclusive of the aspects of behaviors, ways of thinking, and lifestyles will be addressed in regard to what influences biodiversity has on cultural diversity and likewise what cultural diversity appears due to the biodiversity.

Within the investigation method, this core is understood by dealing with material aspects and phenomenal aspects of human beings, but also in-depth and interpretative facets (Lee, 2015). Together, these are laid as a foundational base regarding the culture and the environment. With this approach, the qualitative research method provides important research materials that quantitative research alone cannot provide. By carrying out both qualitative and quantitative research methodologies, with respect to the interdisciplinary convergence research of biodiversity and cultural diversity, a new vision can be provided in regard to developing the knowledge of the islands into an accessible resource.

The islands each possess a uniqueness not found elsewhere, through the distinctiveness of an island, and an island between the sea and the inland. The special, ecological features that each island maintains, the lives of the residents also possess unique cultural styles. The following research is proceeded with in order to recognize the importance of the TEK for wise use of bio-resources of the islands, coastal areas, preservations, excavation planning, and continuation of 
the TEK of biocultural diversity. A sustainable management system model related to the TK and collection practices of the local communities will be strived for. The analysis of the socio-cultural processes of the local communities surrounding collection practices are the research frameworks of the TK practices of the collections of seaweeds and shellfish. We intend to look at how the residents utilize the TK in the ecology for acquisition of limited resources of the islands. It is also examined for use based on unique collection practices of island areas, ecological and socio-cultural relationships, and diverse organisms distinct to the area and environment, as well as the distribution of cultural diversity. Furthermore, the research will contribute to making a compiled resource by collecting, classifying, and organizing the correlation between the organisms and cultural diversity. The system of identifying sea TK as recognized by the fishermen, the methods of using the resources, and the TK of the residents. In this research, we will strive to preserve the taxonomic TK of the local residents; the participatory observations and onsite investigations will become the foundation. The questions during in-depth interviews related to the TK grasp the orientation of the questionnaire after the onsite, participatory observations have been completed. The questionnaire focuses on the methods of using resources with regard to the practices of collection of seaweeds, shellfish, and how the knowledge is transmitted to descendants.

\section{The fishing village communities and the native foods of the islands}

Culture is a psychological and material lifestyle that the human beings create while living (Hegarty and O'Mahony, 2001). Because of this, culture receives influences from nature and the social environment. Food culture, which is often negligently considered in research despite the fact that it is the most important aspect for human beings for survival, gets determined according to the natural environment and social ideals.

In the island regions where the diverse marine species are discovered, the food culture that has evolved and adapted to the ecological environment has been formed and transmitted through generations. The table menu of the island areas illustrates the vast difference from that of the inlands. The biggest difference is shown with the foods that are used for the ceremonial rites. Not only are the foods of the diverse kinds enjoyed by utilizing the marine creatures that were collected from the proximities of the island, but, also, by projecting the religious ideas to the rite foods, thus, a new dining culture has been formed.

\section{An interview investigation on the recognition and collection of the medicinal herbs and the dietary therapy}

From the folklore viewpoint, this research is intended to be carried out regarding the medical folk traditions and intellectual properties of the island people utilizing biocultural resources. This is based on the understanding of the biological diversity and cultural diversity. Research in the category of the medical folk, includes but is not limited to the following: ideas, proverbs, maxims, taboo words, medicinal songs related to illness, actions for treating/ preventing the illnesses, drug therapies, physical therapies, magic therapies, seasonal folk entertainment, rites, circumstances of eating and living. In medical folk, transmission therapy has maintained the communication ability through the experiences. Oral transmissions and the records have been passed along between the generations as well as between neighbors, along with parties who organize the community. This information is linked with the TK. As a result of the knowledge activities based on these traditions, the TK is the knowledge system that is inherent in the technologies or the creations that have been created. The folk remedies of TK systems, possess value as TK and can be considered a public asset. It is in this 
recognition that TK systems have an empirical scientific method to treat illnesses with regard that it is a knowledge system, valid in its own merits, occurring between the individuals and the groups in the community societies.

The medical folk of island areas have long been transmitting knowledge based on the ecological environment and regional culture. In addition to the empirical approaches regarding the various kinds of dietary therapies and physical treatment methods which have positioned themselves as 'rational' therapies, the work of recognition of illnesses, understanding of medical treatments as cultural phenomena, and interpretation of layers of cultural awareness and meanings must accompany the research.

The researchers will focus on the curing practices of the island people. Specific case examples will be collected by classifying the drug therapies specified utilizing animals, plants, physical therapies including those that give the human body physical stimulations, combination therapies that carry out drug therapy and physical therapy at the same time, magic therapy including magic, taboos, and preventions. The methods of preparing the drugs will be examined according but not limited to: to the time of collection of medicinal herbs, methods of processing, symptoms, process of taking the method and its effects, process of securing transmission ability, verification of the effectiveness of the drug. The cultural practices and traditions of the island people along with focus on illness-curing processes, causes of the illnesses, eradication of the illnesses, and full recoveries are addressed. At this time, the transmitters of the folk remedies are looked at carefully by classifying them into the groups according to the livelihood.

Specific investigations regarding native words related to various illnesses and medicinal herbs, methods of preparing the drugs in accordance to time of the collection, methods of processing, and symptoms of the medicinal herbs, along with the methods of taking the medicines and subsequent effects, the process of securing transmission ability as verification of the effects, the TK, preparation measures including taboos, side-effects, methods of preventing various illnesses, professional transmitters like medicinal herb collectors, midwives, and civilian acupuncturists, as well as any other practitioners will be examined.

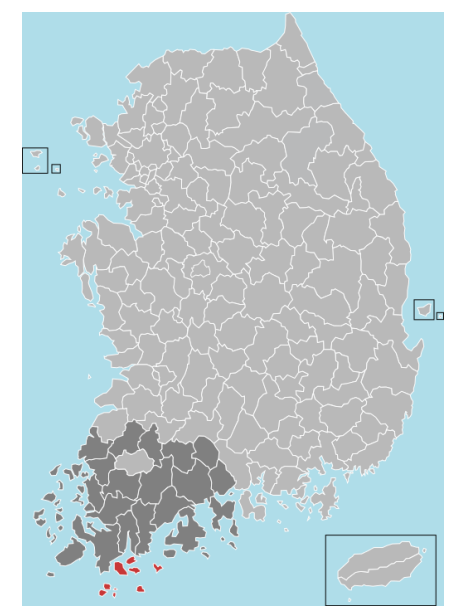

Fig 1. Research area of Wando-county (areas in red) in Jeollanamdo Province (dark gray area) (https://en.wikipedia.org/wiki/Wando_County\#/media/File:South_Jeolla-Wando.svg) 


\section{The collection and the classification of the biological language of an island}

Among the marine place names of Wando, Jeonnam Province, there are marine place names used by the 'Mure k'un' (female divers in Korean terminology via Revised Romanisation) only, which are called the "padabat" (sea field area) of the Mure k'un (female divers). We have considered the diversities of the marine place names, the back place name morphemes that were created by the Mure k'un (Cho, 2015; 2016). The research objective lies in looking at the diversity and distribution of the marine places which were named by the Mure k'un which appear in the marine 'cipee' (traditional fishing) centered on the Cheongsan Island region and the Geumil Island region of Wando, where the Mure k'un have been presently engaged in the activities. The research on language diversities of marine place names are: (1) The appearances of the cipee communities and the Mure k'un; (2) The vocabulary difference between the area of the work of the Mure k'un and the marine topography; and (3) Different morphemes of placing of marine named by the Mure k'un. (4) There is also significance in disclosing language diversity in which the special, marine-topographical characteristics that are recognized by the Mure k'un and are reflected in marine place names with regard to the dialect aspects. Because there is a difference in regard to the morphemic changes, writing the dialect of Wando, Jeollanam-do, this research jointly used the method of morphemic transcriptions according to the International Phonetic Alphabet with regard to the transcription system. For example, the Mure:k'un (female diver), which is one of the dialect forms of this region of female divers, is written as 'mure:k'un'. In this research, the diversity of the specific marine ecological language was looked at through marine place names of Wando, which were specifically created by the female divers of the area. The documentation of the unique cultural diversity of female divers in Wando and the biological diversity are important tasks for discovering the cultural diversity of this marine region. The collection of the data and materials regarding the native language of each region is required. The analysis of the biological language which is applied through the method of measuring dialects of word distances through an analysis and the restoration of the biodiversity must take place.

\section{The archiving of the data on the biocultural diversity}

To establish a database in the resources field, the use of ordinary case examples are created from the DBs by field, including but not limited to: historical and cultural resources DB, cultural resources DB, biological and ecological resources DB, environmental resources DB. The goal and objective of establishment of a resource $D B$, is to aid in searches and provide better utilization from information through making the resources into a DB. If a DB with multiple convergence results occurred within diverse fields is established, it saves considerable time and efforts of researchers, and can support research results in providing a new viewpoint. The intrinsic food culture of an island reflects the changes of the food culture, the fish species, and the fishing activities according to the changes of the ecological resources. One example is the soup named 'Cheongsandotang', of the Cheongsando Island in Wando, is a food that does not have an equivalent. The soup is made thick through dissolving the glutinous rice flour. Instead of a broth being put on the ancestral rite table, the Cheongsandotang is placed on it. Because the sea hares (Aplysia kurodai) from the Cheongsando Island are put into the Cheongsantang, it is a food that uniquely represents the Cheongsando Island. When the sea hares have not been caught, abalones, conches, or other marine species are substituted. The cultural diversity, of island residents and the biological diversity of the surrounding natural resources that are utilized, can be analyzed together. There is a need to understand and interpret islands through such convergence viewpoints and collaborative research efforts. An archive for making such a biocultural diversity effort documented and accessible for benefit of 
knowledge resources shall be established. Furthermore, changes of the lives, customs, formalities, and other important cultural aspects shall be established within this DB. With this convergence research DB, people can search for diverse resources information and access information about the changes of resources that shift according to time and the environment.

\section{The development of a biocultural diversity index using the species diversity index}

Presently, the importance of species diversity has been recognized as being higher than at any time in the past, and efforts have been made for the preservation of species diversity in multiple ways. Species diversity is also recognized as an important index for judging the soundness and the sustainability of the ecosystem (Maffi, 2007; Zent, 2008). The recognition of importance of species diversity has been used as a basic index with which the condition of the ecosystem of the region can be shown. In the same way, the biocultural diversity index, can play a very important role as an index which represents the condition of the biocultural diversity of a given region. According to Loh and Harmon (2005), the biocultural diversity on the national level was calculated. The cultural diversity index took the indices of the languages, the regions, and the minority ethnic groups as the subjects of the measurements. The biocultural diversity index was calculated with the average number of the mammals and the average number of the plant species of the country as the bases. The biocultural diversity index was calculated by using such diverse indices (Joško and Jelena, 2016). The results were that the calculations were that Papua New Guinea was the highest, next was French Guiana, and the third was Suriname. Also, Maffi and Woodley (2010) said that the places in which the language diversities were high indicated the regions in which the species diversities occurred. Based on this, it was concluded that the places in which the cultural diversities were high also had corresponding high species diversity.

With limited resources, the island regions have many good case examples where the people living in these areas have sustainably utilized area resources for long periods of time. However, with modernity many of the cultural traditions have been disappearing due to the rapid material and cultural exchanges with the areas outside the island. Species diversities have been rapidly reducing in numbers. The biocultural diversities of island regions are more easily influenced compared to the continents, which hold larger land masses (Zharikov et al., 2005). Accordingly, use of the biocultural diversity index will be accessible as a document useable for understanding and preserving the condition of biocultural diversity of a region through utilization of the biocultural diversity index.

\section{Results and Discussion}

\section{Island biocultural diversity and its ecogeographical distributions}

Aspects of a given culture often reflect the adaptation of humans to the natural environment. The intrinsic and cultural characteristics of a specific region frequently reflect the natural environment of the region. Hence, in order to effectively understand the culture of a certain region, three-dimensional considerations regarding the natural environment, including the geography, topography, ecology, of the region, are needed (King et al., 2003; Whittaker and Fernandez-Palacios, 2007). The islands and seas have influenced cultural actions of humans, after having initiated use of the ecological 
environment. They have also been having enormous influences on mutual evolutions, between organisms and humans. In Korea, a maritime country, environmental and ecological research of the islands and the seas have been disproportionately weak in comparison with land ecosystem research endeavors. Despite this, one thing that is clear is that we know from a biogeographical viewpoint, the ecological complexity develops from interaction between humans and nature. The cultural diversity that takes place during the process of adaptation to the environment has been reproduced through expansion to the islands, coasts, and inlands.

The important research agenda for addressing and overcoming the ecological crisis that mankind has been confronted recently to include analyzing natural environments and biological resources of islands and seas. This addressment infers information regarding the environments of the past and the present along with researching influences of humans on the environment. Establishment of culture is a process that developed concurrently while humans adapted to their natural ecosystem and established societies. We have learned through history that there are very intimate interactions between the utilization of natural resources and the survival of mankind. There is no doubt that the amount of tangible and intangible resources that are needed by humans to live, have been intrinsically connected to surrounding natural resources. It was the resulting process of adaptation to the environment of humans who settled here.

The goal of this research task was to understand the types and forms of the main creatures, the distribution of resources, the present use of biological resources by residents based on the data and materials of investigations into the biological resources of manned islands and unmanned islands of Wando-gun. A basic format that will allow for the information to be clearly understood will result after deciding on investigation items of the biocultural diversity which will be inserted into the data base. The spatial range of the investigation shall be limited to Wando-gun. The information on use of the biological resources and information on TK regarding Wando-gun islands will be better understood. Initially, it is necessary to distinguish the shores and islands of other regions of the southwestern sea, and distinguishing behavioral patterns and uses of biological resources from those who have been managing resources and whose lives centered on the seas. The spatio-temporal changes of the island shores shall be carried out through the ecological method of researching the wide use of the land and the physical, spatial structures. The biocultural diversity drawings shall be established and analyzed by introducing a geographical information system that can indicate distributions of biocultural diversity in a space and then transferring the information into digital format. Multidisciplinary convergence research shall be carried out through direct and indirect information exchanges and the joint investigations regarding the humanities field, which requires TEK, understanding regarding natural science and the biological environment. Classifications of separate multidisciplinary research will be conducted on the spatio-temporal interactions of human and nature on the islands and seas. Through comparatively analyzing the case examples in Korea and overseas, the concept of biocultural diversity that can be utilized in Korea will be organized and the methodology identified. Using the quantitative method regarding biological diversity, the relationship between the abundance of biological diversity and cultural diversity will be comparatively analyzed. 


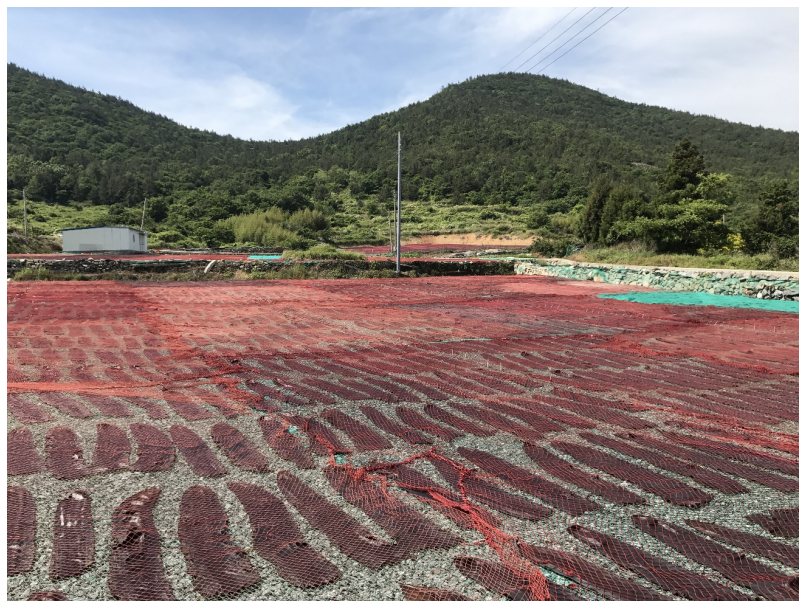

Fig 2. Islanders' life in Saengildo, Wando county is strongly depending on sea cultivation (Photo: drying of sea vegetable, Laminaria japonica). Photo by S.K. Hong.

\section{The understanding from an anthropological viewpoint and the Traditional Ecological Knowledge}

The development of TEK must be understood through convergence research of the biodiversity and cultural diversity. In particular, it is intended to investigate how the residents have been utilizing TEK for expert use in collection of the seaweeds and shellfishes among the biological resources. A plan developed for establishment of the data and materials along with developing information into contents for the resource. This convergence research utilizes case examples the contents will become a precious asset for the future. Hence, researching a plan for utilizing TEK for the wise use of biological resources of the islands, the method of the convergence research shall be adopted.

The TEK will provide information to better assist in understanding the value of mutual dependence between humans and nature along with the value of diversity (Lee, 2015). Therefore, the TEK can not only become an important source for education of sustainability for the residents but also become a vital path for delivery of the wisdom transmitted through generations. In order to carry out the research on how residents have been making, preserving, transmitting, and utilizing TEK, the convergence research between cultural sciences and natural sciences is needed. Most of the previous research had stopped at the accumulation of data and materials, leaving establishment of a database and the utilizations of the archives uncompleted. In contrast, this research does not end with a simple accumulation of the data and materials. Through the excavations of TEK information, information on how the resources have been acquired, how the residents have been effectively using these resources can be revealed. The delivery of knowledge resources accumulated which will benefit future generations was one aspect of originality of this research. The seas of Wando-gun possess extraordinary species diversity. Because of this, the research does not end with simply documenting the different kinds of the main organisms, but rather continues investigating the understanding distribution of resources, present uses, and other relevant data through a multifaceted investigation. Our team looked at what kinds of resources are distributed based on the spaces and environments of the islands.

In the cases of Shinjido and Yeoseodo in Wando, the female divers have been in charge of the collection of the seaweeds and the shellfishes and must go into dangerous seas to collect these items. Although the female divers are native in 
these areas, there are female divers who journeyed over from Jejudo and have settled in the area; as such, female divers of the island villages coexist. The environments and resources of the sea spaces recognized by the native female divers in Wando are different from the sea spaces recognized by the Jeju female divers. The environments of sea spaces recognized by female divers is learned information in accordance with TEK that has been transmitted. The method of the diving, the sounds of the finishing breaths (sumbisori), and the method of using the implement for picking the abalone (bitchang), in their entirety, are developed by the basis of TK and expanded with TEK. The female divers from Jeju are extraordinary in terms of the technical aspects of their collection skills and have been recognizing the special spaces in which the resources are distributed. The female divers obtain TEK information, passed down to them matrilineally regarding the places where resources must be collected, and where these are distributed. Female divers know the topographies within the sea, obtaining the diverse collection methods from inheritance of the TK. Over time they also learn the skills of holding their breath and techniques for enduring the cold sea through TK methods. The diversity of sea resources assists female divers propagate the cultural diversity. There are many differences between biological resources, including but not limited to: abalones, sea cucumbers, sea squirts, octopuses, conches, seaweeds (sea mustards, kelps, and Gelidium divaricatum), the tools for collecting are different. Even within the same sea, methods of collections are different, names are different, and the methods of the cooking are different. To that extent, the more extraordinary the species diversity is, the further the cultural diversity also gets developed. The collection rules and knowledge of the female divers for maintaining a sustainable society are an issue which the research must advance.

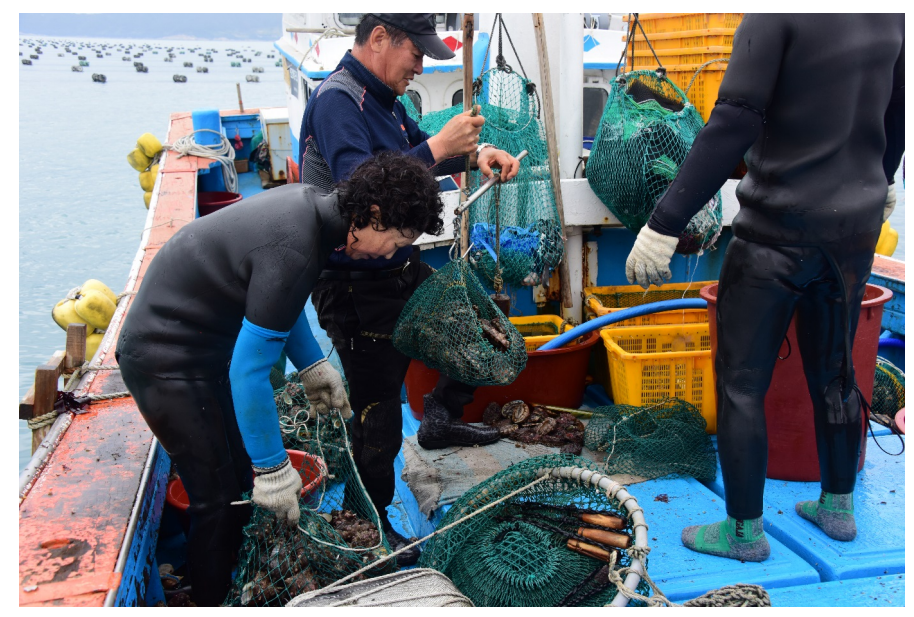

Fig 3. Activity of Haenyeo (Women divers) collecting abalone, sea cucumbers and other mollusks (Cheongsando). Photo by S.K. Hong.

Sustainable developments have been taking place between humans and nature harmonizing with one another. The preservation of TK possesses the opportunities for achieving ecologically sound growths by wisely using the resources. It is our intent to documenting the wisdom and knowledge of ancestors who communicated with nature, who adapted to the logic of nature, whose intent was to make use of items within the scope of nature and understood sustainable practice intended on not harming natural resources. The material practices of collections require the formulation of countermeasures in order to preserve, maintain and continue sustainable development due to the increasing materialistic collection practices that stem from socio-cultural meanings and values. Due to the development of the 
fishing technologies, including overfishing as well as other aspects, the catches of naturally-produced seaweeds and shellfish have been drastically reduced. The maintenance, and sustainability practices for species have become difficult.

The researchers will concentrate on the preparation of a plan for preserving traditional collection practices and for the sustainable fishing village society through this research. When analyzed comprehensively, the transmitted knowledge on collection of seaweeds and shellfish shows the special features of co-working technologies, the simple collection technologies, and the labor-saving technologies that have been ongoing. Because most of the objects of TK have remained at a fragmentary information collection level only. Missing specific investigation viewpoints, the data and materials verification and evaluations are in question regarding whether these, do indeed, possess the conditions for being valid TK.

As a result, the importance of TEK for wise use of bioresources on the islands and coastal areas is recognized. The research proceeds with the goal for preservations, excavations, and diffusions of TEK and biocultural diversity.

This research analyzes the processes which have been based on traditional fishing knowledge contained in the technologies of collections of seaweeds and shellfish (see Table 1). Fishing and collection comprises one of the main livelihoods of women in Donggo Village, Shinjido, Wando-gun, Jeollanam-do. These actions and recognitions possessed by the collecting group are not simply the practices or customs that have been passed down from older generations. The fishermen understand that TK that has been transmitted from the ancestors is scientific and is a realistic wisdom; as such, they actively utilize it when they work. They pay attention to aspects in which they organize the process of TEK so that the fishing knowledge remains interact but is combined with new technologies, and fishing gear developments.

Table 1. Relationship among biodiversity, language diversity, cultural diversity and Traditional Knowledge

\begin{tabular}{|l|l|l|l|}
\hline Biodiversity & $\begin{array}{l}\text { Language } \\
\text { diversity }\end{array}$ & $\begin{array}{c}\text { Cultural } \\
\text { diversity }\end{array}$ & \multicolumn{1}{c|}{ Traditional Knowledge } \\
\hline Abalones & $\begin{array}{l}\text { Abalones } \\
\text { / Jeonbok } \\
\text { / Small } \\
\text { abalones } \\
\text { / Blue } \\
\text { abalones } \\
\text { / }\end{array}$ & $\begin{array}{l}\text { Native } \\
\text { language / } \\
\text { Collection } \\
\text { method / } \\
\text { Tools and } \\
\text { technologies } \\
\text { / Distribution } \\
\text { method / } \\
\text { Sales / } \\
\text { Native foods } \\
\text { / Medical } \\
\text { folk }\end{array}$ & $\begin{array}{l}\text { In the whole area of Wando, they call 'abalones' "jeonbok". Rather than eating them as the daily food, most of } \\
\text { the abalones that were collected are commercialized. In the past, at the fishing villages, together with the sea } \\
\text { of the abalones are used as the important tools of the fishing village society. } \\
\text { as the temporary tools for picking the wild greens. Also, although the abalone shells are used as the } \\
\text { manufacturing raw materials, too, of the handicrafts, including the mother-of-pearls, the buttons, the necklaces, } \\
\text { etc., by making the meat broth with the abalone shells, the foods are made and eaten, too. Especially, as there } \\
\text { is a lot of protein and minerals, the digestion and the absorption get done well. And, because they are excellent } \\
\text { for the nerves recovery, they are a food that is eaten a lot as a health food in the summer season and is eaten a } \\
\text { lot by patients and the mothers who gave birth, because the abalones are precious, instead of eating, the } \\
\text { residents have been selling them as products and, by boiling the abalone shells, the broth has been made and } \\
\text { drunk. }\end{array}$ \\
\hline
\end{tabular}

\section{Local foods and biocultural diversity of the island and seashore areas}

High tide is very important to the island residents who have been living with the sea as their livelihood base. Not only is high tide the optimal time for collecting seaweeds, which include sea mustards, lavers, and Hijiki (Sargassum fusiforme, syn. Hizikia fusiformis), but it is also the time to go out for fishing activities. The livelihoods of the island residents have 
direct relationships with the high tides, and they have influences on the culture as well. It is hard to find traces of behaviors that transpired in the past, or of rituals which occurred related to the sea. These rituals did not pertain only to the ship owner's possession and the sailors to whom the fishing was a livelihood. When the ships were not mechanized, the residents who lived on the islands had a heightened sense of danger and of dying. Being surrounded by the sea on an island proved to be difficult. It was common custom to solve grudges, as well as the pains caused from sudden deaths through the customary traditional rituals.

The rituals that related to the sea were proceeded with, according to the high tide. Commonly the rituals began when the water came 'alive' with the rising tide, and rituals were finished at the low tide when the water receded. Fishing activities using the ships coincided with tide movements. The act of fishing took place when the tide was rising tide and the return from fishing took place with the low tide. The island residents do not see the sea water as separate but view it rather as an organic being with an identity itself and have been recognizing it as such. Because of this recognition, island residents have been expressing the rising tide and the low tide as 'the water is coming alive' and 'the water is dying', respectively. To the island residents, the sea is the basis of life and also the culture.

Looking at the aspects of changes of community rituals that have been taking place in the island regions of Korea, it is clear that they are largely classified into the following four categories:

- First, the severance and resulting simplification of the village exorcism ('gut' in Korean term) due to industrialization, urbanization, ageing, and religious problems. In village exorcisms ('gut'), where the villages have overcome the crisis of severances and simplifications, the rituals are acted out in a form that is different from prior to the events occurring. For example, a change of the holiday responding in a change of the fisheries activities. The smooth mobilization of manpower and transformation by accepting only the necessary aspects after excluding the ritual behaviors by accommodating the folk culture is regularly occurring.

- Second, in the case of some of the village exorcisms (gut), where preservation values are extraordinary, rituals have been designated as intangible cultural assets, and have been receiving management and support according to the cultural policies. The 'Ttibaennori' (Ttibae Boat Festival) of Wido, Jeonbuk, the 'Bunggipungeoje' (Bunggi Big Catch Festival) in Hwangdo, Taean-gun, Chungnam, the Gochanggut (Gochang Exorcism [gut]) in Wepo-ri, Ganghwa, Incheon Metropolitan City, and the 'Anseompungeoje' (Anseom Big Catch Festival) in Dangjin-gun, Chungnam can be mentioned as representative examples of these types of designations. In these cases where the community rituals are continued, many kinds of side-effects occur due to restrictions resulting from designations of intangible cultural assets.

- Third, the places that strive to make community rituals into common practice in order to break through a stagnant village economy, via utilizing said rituals in tourism businesses, have been increasing. The Big Catch Festival (Pungeoje) that has been carried out in Chujado is one example.

- Fourth, although a rare case example, village economies have been improving because of developments of the aquaculture industry, the fisheries, and the tourism industry, there are the regions where community rituals had been suspended but because residents have demanded a resurrection of a ceremony, they reappeared again or were created anew. In these rare cases, either the fete day was changed according to changes in the ecological environment or an aspect was added or excluded during the process of the proposal. Wando is one example of these rare cases.

In the early 1970s, the aquaculture centered on laver and oysters, and then has expanded nationwide since the 2000s, as a result diversity increased within species. Seaweed aquaculture in the early 1970 s had been attempted through 
receiving active support of the government. Overfishing occurred due to use of nylon nets and motorizations as well as expansion of fishing ships. Since the latter half of the 1960s, the fish resources had been drastically reduced. Reduction of fish resources had direct, economic blows not only to fishermen but the island residents as well, who received indirect benefits of fishing activities. In order to reduce economic damages to the fishermen and island residents, the government actively encouraged aquaculture of laver, oysters, and other species through supportive policies. The region where aquacultures practices had been attempted in accordance with support from the government was south of a designated fishing restriction line. This area included the five most impacted islands in the Yellow Sea: Yeonpyeong Island, Baengnyeongdo, Daecheongdo, Socheongdo and U Island.

Wando-gun is a place where diverse seaweeds have been produced successfully, so much so, that the international 'Wando Seaweeds Expo' has been held. The amount of seaweed production in Wando-gun is the highest in the country. Seventy percent of the amount of the production of kelp in the country, and sixty percent of the total amount of production of Hijiki (Sargassum fusiforme) in the country occur in this region. The aquaculture of not only seaweeds but, also fish and shellfish have been vigorously cultivated, along with abalones production ranking at eighty-one percent of the country. Wando is a place where the fishing and aquaculture industry have been actively thriving, to the extent that it has been called "the heaven of the seaweeds". Most of the seaweed that has been produced in Wando has been through aquaculture.

The laver aquaculture of Wando began during the era of the Japanese colonial rule of Korea, a time earlier than the time of the five islands in the Yellow Sea (Yeonpyeong Island, Baengnyeongdo, Daecheongdo, Socheongdo and U Island), striving for attempts in accordance with active support by the government. The aquacultures of diverse kinds of marine products, including kelp, Hijiki (Sargassum fusiforme), sea mustards, seaweed fulvescens (Capsosiphon fulvescens), laver, abalones, fish, have been taking place. Such diverse aquacultures of species led to economic stability of the Wando residents. Economic security of the residents played an important role of continuing the community rituals specifically related to species diversity. The community rituals that are being carried out in Wando presently have become increasingly different from those that have occurred in the past. The most notable changes can be found in the times, processes of the carrying out the ancestral rites, the methods, as well as other aspects. Such changes are speculated to be the results of having adapted to changes of social and ecological environments.

The production of diverse species has also influenced the eating habits of the Wando residents. The common table food items of Wando, which regularly serves diverse food species, is quite different from those foods of other regions. The native foods, which have distinct characteristics of Wando, have not disappeared and are a regular table staples even presently. The diverse native foods in Wando are arranged on the alter table when ancestral rites are performed on holidays. For example, placed on the memorial table of Saengildo, Wando are: octopus, sea cucumbers, oysters, shells, clams (Manila clams), gunbo, dolsuosa, abalones, black snails (sea hares). A soup is created utilizing these native species. Although the foods are different from each other, and made by using raw materials, the name is unified with one word: "tang" (soup). All of the native foods of Wando that are called "tang" (soup) are cooked by using the seafood that are produced in Wando. The distinction of the native foods of Wando appear even more clearly distinct when compared with those of other regions. The local government that is comprised of the most islands in Jeollanam-do (Province) is Shinan-gun. Looking at the memorial service tables of Amtae, Jaeun, Palgeum, where the islands' distances to the lands are similar to those of Saengildo, Wando, the islands belonging to Shinan-gun, are nearly similar with the table settings of the inlands. This, despite the fact that these are islands rather than inland areas. Because the residents residing in island 
areas on the coasts of Shinan-gun have been living lives based on agriculture rather than fisheries, the food culture is similar to that of the inlands. It is also difficult to find the special, native foods of those areas presently.

As a result, there is a need to focus on the diversity of food culture that has been maintained and enjoyed by Wando residents. By determining the native foods of Wando through meticulous onsite investigations, their original forms will be able to be preserved, since these items can disappear rapidly due to environmental changes. The work of understanding the performance aspects of community rituals of Wando-gun is needed because there have been changes that have occurred and also due to the aquacultures of diverse species. It is highly expected that such work will bring about meaningful results in examining what influences changes of the ecological environment have been having on the lives of residents, and how residents, react to the changes of the environment to accommodate this change process.

\section{Medical folk traditions utilizing biocultural resources}

Civilian medical treatments are the natural curing methods that are believed to raise immunity function and recovery capability. They are believed to possess effectiveness in promoting the illness-curing effects. The traditions of these civilian medical treatments can be commonly called "medical folk". Here included, are the ideas, proverbs, maxims, taboo words, medicinal poems, therapies, and prevention actions, drug therapy, physical therapy, magic therapy, seasonal folk entertainments, rituals, livelihood circumstance.

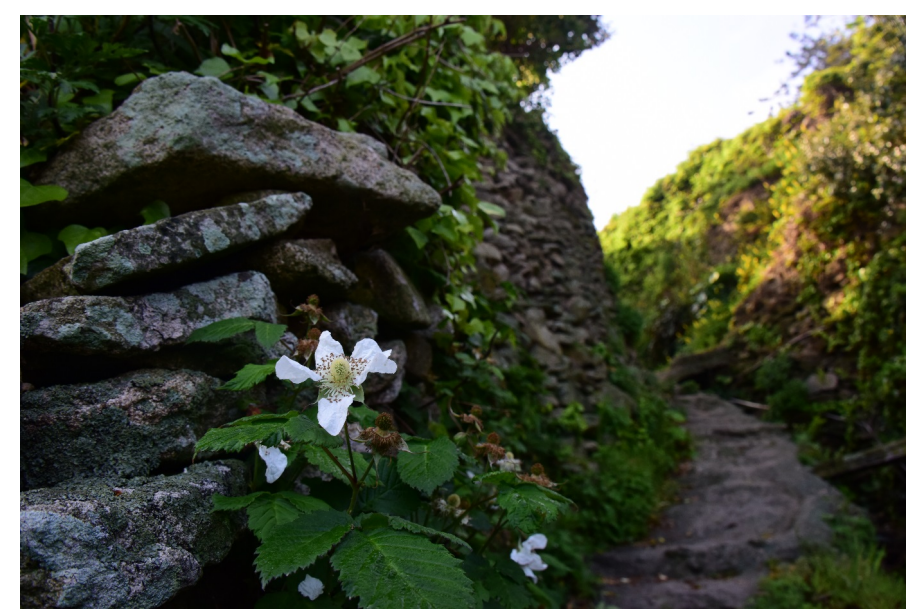

Fig 4. Plants in island are sometimes used for medicine and vegetables (Yeoseodo, Wando). Photo by S.K. Hong.

Medical folk knowledge belongs to the TK of which the experiential effects have been widely recognized by being passed through generations. This TK is indeed, the folk knowledge that has been transmitted to the civilians. This is the knowledge that has been accumulated by the general, ordinary people for a long time. Mostly, there are many cases in which it is orally transmitted by being passed through many generations, or, in which it is acquired through direct and indirect experiences. The spirits and values are a type of material culture, and can be seen as products of knowledge in an open category. The medical folk includes the folk curing actions, experiences, TK, that have been transmitted within life cultures of the ordinary people. 
Medical folklore has been sporadically researched in the natural science field, the social science field, and the humanities field. In the case of the field of natural science, topics such as Korean medicine, preventive medicine, pharmacology, health studies the research focuses on more functional aspects, including clinical analyses of civilian therapies, special pharmacological characteristics of the animals, plants, and minerals have occurred. In the middle of the 1970s, when the limitations of modern medicine were recognized in Korea, research on the civilian therapies became diffused. Entering into the 1980s, research for verifying actual efficacies of civilian therapies had been intensively taking place. The value of civilian therapy began to be recognized as an alternative medicine that heightens the effects of medical treatment of illnesses of modern medicine. This was done through making the natural healing capability of the human body rise via reinforcements of immunity functions and recovery capability. Ever since the Convention on Biological Diversity 1992 was adopted, a high value and marketability of traditional medicine and drug knowledge began to receive the attention centered on the World Intellectual Property Organization (WIPO).

In studying the unique subculture of TK, medical folklore reflects the special, cultural characteristics of the island shores in Jeonnam is a very pertinent subject of research. In particular the documentation of the medical folk as the TK regarding the wild-growing plants, and marine resources in the area of the 'Dadohae' Archipelago in Jeonnam, including the manned islands and unmanned islands, is necessary. Future-oriented convergence research inquiring about the biocultural diversities is needed, given the interest in TK, the investigation on medical treatment methods of the civilians. This research has meaning with regard to the point that, instead of being the sporadic listings regarding civilian medicine, expansion is possible with specific discussions on the true nature of the native society. This discussion, which satisfies the requirements criteria of $\mathrm{TK}$, the processes of transmission between generations, the ecology-cultural background, and actual condition of utilizations is vitally important to current ongoing conditions.

Medical folklore is an empirical science which has been undergoing time tested clinical experiments and the wisdom of the life which has been learned through successive generations by the local people. The medical folklore of the islandcoastal areas in Jeonnam has been transmitted within a mutual relationship between the natural environment and the human environment of marine areas, including rivers, coasts, and the island environments. In situations where benefits of medical organizations are difficult to be received, or where medical costs are difficult to be paid, civilian medicine has been the same as the properties of free sharing, which helps protects lifeways.

\section{Biocultural diversity of the islands in a language-ecological viewpoint}

Mankind has succeeded in survival by collecting the diverse plants and overcoming threats by beasts in the surrounding ecological environment. By accumulating knowledge, such as the use of fire, and the production of the tools, among other skills, and through successfully transferring their ecological language regarding TEK that has been accumulated, sustainable growth has been achieved. Meya (2006) had stated that human beings remember, record, and transmit their TEK in the form of a language. The ecological language of a region cannot be separated from the TEK of the region. The ecological language plays a decisive role in maintaining the biocultural diversity of the region (Maffi, 2001; Pretty et al., 2009).

However, the 'Atlas of the World's Languages in Danger of Disappearing', UNESCO (2005) stated that a half of the whole world's languages are faced with the crises of extinction and that around $90 \%$ of the oral statement languages will nearly become extinct around the time this century ends. Also, according to Zent (2008), it was pointed out that habitats of the ecosystem are disappearing, and the environment is being destroyed due to the climate change. Along with 
indiscriminate developments, indigenous organisms which have contributed to the maintenance of the traditional cultures, will disappear. With the disappearance of the indigenous species, the knowledge, which has been traditionally known and associated regarding the organisms will disappear. The language that maintains the organisms and the culture, will also become extinct. The convergence research of biocultural diversity must maintain and preserve the TEK and it must present a customized resource plan for the region which can assist coping with the crisis (Berkes et al., 2000; Maffi, 2007; Ambio and Karim-Aly, 2009). This will be possible when the interdisciplinary, mutual connections for the restoration of the TEK of biological diversity, cultural diversity, and language diversity regarding the biocultural diversity of the region are materialized. This is the starting point that aims at sustainable development of biocultural diversity of the region and, at the same time, is the convergence research that can assist in discovering the sustainability choices for future societies.

We think that this research possesses a unique outstanding difference when compared with the previous dialect and language research in regard to the point that it is an ecological language research in the language-ecological viewpoint based in convergence parameter viewpoints. The purpose lies in making a database of specific lists, excavation of an agenda of ecological language for the revelation and restoration of ecological knowledge and the TEK which is reflected in the cognitive system of the regional residents. By developing a plan for ecological-language diversity for coping with a crisis of biocultural diversity and creating a resource for utilization, research focused on the sustainability of developments of the region and the society will proceed.

The collection and the analytical research of the traditional ecological language shows differentiations in the region through direct and indirect investigations based on onsite investigations in the language-ecological aspect. The trends were looked at through the traditional distance measurement method. A specific case example, the Sangseo Village in Cheongsando is a village where there are the stone walls named with the native words 'stone mound' and 'stone pile'. In the Wando region, it has been designated as the 'stone wall village' and has been preserved. At the Sangseo Village, a creature that is more well-known than the stone walls was discovered. It was 'Joribokjaengi Saebi' (Tadpole Shrimp). This freshwater organism 'Ginkkoritugusaewu' (Longtail Tadpole Shrimp) is in the crisis of becoming extinct. During the month of May, Cheongsando becomes crowded with tourists, sometimes over 4,000 people per day who come there to see the creature. The habitat of the 'Ginkkoritugusaewu', in one area of the 'Sangseo Village', among the twenty-three administrative areas of Cheongsando, has been identified as a habitat. As a result of having proceeded with onsite investigations and in-depth interviews of residents in order to find the habitats of the 'Ginkkoritugusaewu', residents expressed the 'Ginkkoritugusaewu' as the 'Joribokjaengi' in interview investigations (Cho, 2015; 2016). During the dry period before May, Ginkkoritugusaewu stays within the ground, but when the rains return during May, and rice paddies are filled with water, they emerge and freely submerge within the mud. According to reports, one special feature of the Ginkkoritugusaewu is that its lifespan is short. It is said that the lifespan ends on or around the twentieth day. To the residents of Cheongsando, it is a creature that has been considered as a headache that had interfered with the farming in the past. It is well known as Joribokjaengi Saebi that submerges in the mud. Such convergence research has significance, for the ability in restoring the TEK of the region through the revelation of ecological knowledge and in securing biological diversities of the islands. 


\section{Database and knowledge contents using biocultural diversity resources}

Through a pilot study investigation and subsequent analysis, the present situation, classification system, service methods, of the sites that have established the DB's in the resources field in Korea shall be investigated. The establishments of the DB sites, including the history and culture DB's, the life culture DB's, the ecological DB's, the environmental DB's, the cultural contents DB's, will be analyzed. The classification systems, search services, utilization plans, will all be investigated. With this perspective as the basis, we propose to establish a resource as well as establish an archive, through the convergence research of cultural diversity and biological diversity of the island regions. The indigenous food culture of an island reflects the changes of the food culture, the fish species, and the fishing activities resulting from the changes of the ecological resources. Regarding such changes, research results shall be provided so that food culture can be searched and so that the changes of the food culture can be known through the establishment of a DB. Based on this, the information provision for the development of the contents and the plan for the utilization in the diverse fields based on the DB, and a plan for the utilization as a contents development bank are presented. The classification of the data and the methods are the following:

- First, regarding the method for the selection of the keywords, the contents on the general topic, culture, organisms, convergence topics, are arranged in the first half of the ISA hierarchy, and the classification subjects that become the subjects of such pre-matureness are selected.

- Second, regarding the hierarchy, the reasonable number of the topics is maintaining relation to the maintenance of the hierarchy between the upper and lower classes (Da Costa, 2002). The reasonable number of topics that have inclusion relationships with upper class must be maintained by subdividing and integrating by considering the number of the topics of the lower class.

- Third, regarding the approach methods resulting from the purpose of the use, in relation to the use of the information related to the topics or the fields that are evenly distributed in the entire web document, in the case in which a search is desired within the scope of the entire or concerned, low-ranking directory, it shall be made so that the searches can be done through a separate interface (provision of a box for the keyword searches and others of the like). The information will be searchable in many fields, including history, prominent figures, cultural assets, folklore, organisms, etc. In the case that information is searched for with the concerned topic, the search will be made possible according to the objective by a separate interface (provision of a box for the keyword searches) which designates whether a search shall be performed within the range below the concerned topic or an expansion shall be carried to the entire fields of the topic.

- Fourth, by providing a regional and geographical approach method as a geographical approach plan, the design shall take place so that the information can be approached geographically (Caeiro et al., 2003).

- Fifth, by providing an approach method according to the type of the file of the source data, including the document types, the media types, the image types, etc., as an approach plan according to the medium, the efficiency resulting from the re-use is heightened. Sixth, the searches via media provide the search functions by literature material, image material, audio material, and video. 


\section{Conclusion and the future plans of this research}

Regarding the core of the interdisciplinary convergence research, the communication between the experts in humanities and natural science is indispensable (Hong and Nakagoshi, 2018; Hong et al., 2014). As a convergence task that ties together the two paradigms of the biological diversity and the cultural diversity, the interdisciplinary research on the biocultural diversity of the islands possesses the differentiation from the previously existent island researches with regard to the point that ecology, anthropology, folklore, linguistics, cultural contents, and landscape ecology meet and excavate and discuss the agendas. Also, it is original with regard to the point that it seeks for the making the knowledge resource utilizing the organisms, the ecology, and the life and culture resources of the islands.

The researchers of this task had proposed a motion at the IUCN General Assembly (5th WCC) that was held in Jeju in September 2012. To the extent that it was adopted as a resolution following the submission of a motion (Strengthening Biocultural Diversity and TEK in Asia-Pacific Island Regions) at the time, this agendum has secured a concept that is internationally and commonly used (Hong, 2013). It is our view that the results and the utilization of this research are very important on the level of seeking responses and plans regarding the extinction of TK, species diversity, and culture of the islands, which have been disappearing daily due to the industrialization, the urbanization, thoughtless developments, and climate change.

Most of the ecological-environment researches have been carried out with the inlands of Korea as the subjects. Actual circumstance of research on the islands and the marine regions is poor. It is believed that the interactions between humans and the natural environment on the islands and marine regions are different from those in the inlands. It is in this regard that the meaning of the research on the islands and the marine regions, which had been spatially alienated, is vitally important. Although the ecological, environment research until now has been taking place mainly focused on the present, in this research the three-dimensional considerations of the ecology and environment are possible time wise by carrying out the research on the environment of the past and present at the same time. These research results can establish the basic data and materials that can understand the special characteristics of biological diversity of the island regions academically. Based on the results, this research can become the foundation of the utilization of the resources which can develop the industries of the future, including the cultural businesses (CT), and the biological industry (BT), of the future. Scientific convergences are possible with similar ecological-scientific research fields, including the ecological landscapes, the ecological cultures, the ecogeography, the ecological tourism. By securing basic data and materials regarding the island cultures that use biological diversity of the islands, and marine regions through such research, the understanding of the marine spaces can be broadened.

The various kinds of the native foods utilizing the creatures of an island have high utilization values as the tourism resources of the island. Research on the dining culture during the solar term times and seasons and various kinds of the rituals, can utilize the native knowledge of the food materials and cooking methods into the resource and better understand the cultural diversity of the island. Biological resources can contribute to the expansion of the medical industry, too. The therapies that have received the verifications of the medical treatments and effects, among the diverse medical folk, are things that have been used in the concerned regions. This can shorten the time period required for the patents, commercialization, and the industrializations. They will contribute to utilizing the civilian therapies of the island regions, of which there are the worries about extinctions due to the absence of transmitters, and the Traditional Knowledge gathered through systematic collection and preservation of medicinal foods for improvements of medicinal 
stuffs, magic, and illnesses into the resource. The knowledge system regarding the dining culture, the dietary treatments, the medicinal stuffs, which are orally transmitted by the local people can be concretized. This will contribute to the examination of the traditional biocultural resources that have been utilized as food materials and medicinal stuffs in the island and coastal regions of Jeonnam Province and to the securing of the intellectual property rights that can protect and preserve these cultural aspects. Furthermore, this data can be utilized for preparing a preparation measure on the national level regarding the Nagoya Protocol.

\section{Acknowledgements}

This research was carried out by supporting of the National Research Foundation of Korea (NRF-2016S1A5B6914181). Our thanks to the local peoples at Cheongsando, Wando for their valuable comments and for giving interviews for this research. Our thanks are extended to all members at Institution for Marine and Island Cultures, Mokpo National University for their giving comment on this research plan and supporting diverse references beyond the border of academic disciplines.

\section{Endnotes}

1. Other than this, in the international agreement, there are the comprehensive regulations regarding 1) the preservation of the biological diversity, 2) the sustainable use of the biological resources, 3) the recognition of the right to access the genetic resources and the sharing of the profits, 4) the designations of the protection areas, 5) the establishment of an organism information system, 6 ) the science and technology cooperation, 7) the cultivation of the capabilities of the developing countries, etc.

\section{References}

Ambio, K., Karim-Aly, S. 2009. Biocultural Diversity and Indigenous Ways of Knowing - Human Ecology in the Arctic. Alberta: Calgary Press.

Berkes, F. 2004. Rethinking community-based conservation. Conserv. Biol. 18(3), 621-630.

Berkes, F., J. Colding, C. Folke, 2000. Rediscovery of traditional ecological knowledge as adaptive management. Ecol. Appl. 10(5), 1251-1262.

Bickhard, M.H., 2015. The social-interactive ontology of language. Ecological Psychology, 27(3), pp.265-277.

Caeiro, S., M. Painho, P. Goovaerts, H. Costa, S. Sousa, 2003. Spatial sampling design for sediment quality assessment in estuaries. Environ. Model. Software, 18(10), 853-859.

Chisholm, H., S., E. Marino, K.P Whyte, K. D. Dello, P.W. Mote, 201x: Indian Time: Time, Seasonality, and Culture in Traditional Ecological Knowledge of Climate Change. In review, Ecological Processes. 
Chisholm, H. S., S.K. Hong, 2017. Islanders of South Korea: Culture, Climate Change, and Traditional ecological knowledge. J. Mar. Isl. Cult. 6(2), 62-74.

Cho, M.-R. 2015. Name of a place of Wando, Jeollanamdo Province - Cheongsando. Chungkye-myon Muan-gun, Jeonnam South Korea, Mokpo National University Press.

Cho, M.-R. 2016. Name of a place of Wando, Jeollanamdo Province - Geumildo. Chungkye-myon Muan-gun, Jeonnam South Korea. Mokpo National University Press.

Craig, M. 1994. Defining 'Evolutionarily Significant Units' for conservation. TREE 9(10), 373-375.

Creese, A. and Blackledge, A., 2011. Ideologies and interactions in multilingual education: What can an ecological approach tell us about bilingual pedagogy. Language policy for the multilingual classroom: Pedagogy of the possible, 82(1).

Da Costa, F. P. 2002. A hierarchical cluster system based on Horton-Strahler rules for river networks. Appl. Math. 109(3), 163-204.

Flenley, J., P. Bahn, 2003. The Enigma of Easter Island. Oxford University Press, UK.

Gadgil, M., F. Berkes, C. Folke, 1993. Indigenous knowledge for biodiversity Conservation. AMBIO 22, 151-156.

Hegarty, J.A., O'Mahony, G.B. 2001. Gastronomy: a phenomenon of cultural expressionism and an aesthetic for living. Intern. J. Hospit. Manag. 20, 3-13.

Hong, S.K., N. Nakagoshi (Eds.), 2018. Landscape Ecology for Sustainable Society. Springer-Verlag.

Hong, S.K., J. Bogaert, Q.W. Min (Eds.), 2014. Biocultural landscapes - Diversity, Functions and Values. Springer-Verlag.

Hong, S.K., Wu, J., Kim, J.E., N. Nakagoshi (Eds.), 2011. Landscape Ecology in Asian Cultures. Springer-Tokyo.

Hong, S.K. 2015. Socio-economic foundation by biocultural resources management: Suggestion for UNESCO Shinan Dadohae Biosphere Reserve, Korea. J. Mar. Isl. Cult. 4, 81-88.

Hong, S.K. 2013. Biocultural diversity conservation for island and islanders: Necessity, goal and activity. J. Mar. Isl. Cult. 2, $102-106$.

Hong, S.K.(a), 2011. Biocultural diversity and traditional ecological knowledge in island regions of Southwestern Korea. J. Ecol. Field Biol. 34(2), 137-147.

Hong, S.K.(b), 2011. Eco-cultural diversity in island and coastal landscapes: conservation and development. In: Hong, S.K., Wu, J., Kim, J.E., Nakagoshi, N. (Eds.), Landscape Ecology in Asian Cultures, Springer-Tokyo, pp. 11-28.

International Conference on Biological and Cultural Diversity. 2010. Working document on a proposed joint program of work on biological and cultural diversity lead by the Secretariat of the Convention on Biodiversity and UNESCO.

International Union Conservation of Nature. AICHI Biodiversity Targets, 2011-2020. Retrieved from https://www.iucn.org/theme/species/ourwork/influencing-policy/convention-biological-diversity-cbd/aichi-targets.

Je, J.G., J. Kim, S.K. Hong, 2014. Shapes of fishing gears in relation to the tidal flat bio-organisms and habitat types in Daebu Island region, Gyeonggi Bay. J. Mar. Isl. Cult 3, 31-40.

Joško, S., Jelena, Š. 2016. Multivariate statistical methods in researching biocultural diversity. Environ. Ecol. Res. 4(1), 21-29.

Kim, L.-K., et al. 2013. Individual Identification using The Multiplex PCR with Microsatellite Markers in Swine. Reproduc. Develop. Biol. 37, 205211.

King, L., T. Skutnabb-Kangas, L. Maffi, D. Harmon, 2003. Sharing a World of Difference: the Earth's Linguistic, Cultural, and Biological Diversity. Paris, UNESCO.

Lee, K.A. 2015. The Life World of Saltpan Workers and Everyday Politics. PhD thesis, Mokpo National University. (Korean with English Abstract) 
Loh, J., Harmon, D. 2005. A global index of biocultural diversity. Ecol. Indicat. 5(3), 231-241.

Maffi, L., Woodley, E. 2010. Biocultural diversity conservation - A global sourcebook. earthscan, London.

Maffi, L. 2007. Biocultural diversity and Sustainability. The Sage Handbook of Environment and Society. pp. 267-277.

Maffi, L. 2001. On Biocultural Diversity. Linking Language, Knowledge and the Environment. Washington \& London: Smithsonian Institution Press.

Maffi, L. 1998. Language: A resource for nature. Nature and resources. UNESCO J. Environ. Nat. Resour. Res., 34(4).

Menzies, C.R. 2006. Ecological knowledge, subsistence, and livelihood practices: the case of the pine mushroom harvest in northwestern British Columbia. Traditional ecological knowledge and natural resource management. CR Menzies (editor). University of Nebraska Press, Lincoln, Nebraska.

Meya, W. 2006. Letter to Financial Times. London, Financial Times.

Nadasdy, P. 1999. The Politics of TEK: Power and the 'Integration' of Knowledge. Arctic Anthropology 36(1-2):1-18. (Republished in Natural Resources and Aboriginal People in Canada: Readings, Cases and Commentary. R. Bone and R. Anderson, eds. 1st and 2nd (revised) editions. York, Ontario: Captus Press, 2003 and 2009).

Pennycook, A., 2004. Language Policy and Ehe Ecological Turn. Language policy, 3(3), pp.213-239.

Pretty, J., Adams, B., Berkes, F., Ferreira de Athayde, S., Dudley, N., Hunn, E., Maffi, L., Milton, K., Rapport, D., Robbins, P., Sterling, E., Stolton, S., Tsing, A., Vintinner, E., Pilgrim, S. 2009. The intersection of biological diversity and cultural diversity: towards integration. Conserv. Soc. 7(2), 100-112.

Rapport, D.J. 2006. Sustainability science: An ecohealth perspective. Sustainability Science 2(1), 77-84.

Richard, F. 2010. Challenges and opportunities of genetic approaches to biological conservation. Biol. Conserv. 143, $1919-1927$.

Donaldson, T.J., R.F. Myers, 2014. Biogeography of tidal mud flat and estuarine fishes of the Western Pacific including the Indo-Malayan Triangle. Nature and Culture of Tidal Flats in the Western Pacific. H. Yamashita, Li S. (Eds.). Tokai University Press, Japan.

UNESCO Declaration on Cultural Diversity. http://unesdoc.unesco.org/images/0012/001271/127160m.pdf

Whittaker, R.J., Fernandez-Palacios, J.M. 2007. Island Biogeography-Ecology, Evolution, and Conservation. Oxford University Press.

UNESCO, 2010. UNESCO World Report: Investing in Cultural Diversity and Intercultural Dialogue. Paris, UNESCO.

UNESCO, 2005. United Nations Decade of education for sustainable development. 2005-2014: International implementation scheme. Paris, UNESCO.

Zent, S., 2008. Methodology for developing a vitality index of traditional environmental knowledge (VITEK). Salt Spring Island, CA, Terralingua.

Zharikov, Y., G.A. Skilleter, N.R. Loneragan, T. Taranto, B.E. Cameron, 2005. Mapping and characterizing subtropical estuarine landscapes using aerial photography and GIS for potential application in wildlife conservation and management. Biol. Conserv. 125, 87-100. 